\title{
Anisotropic dynamic fracture and energy dissipation characteristics of interbedded marble subjected to multi-level uniaxial compressive cyclic loading
}

yu wang ${ }^{1}$, jianqiang han ${ }^{2}$, junyu ren ${ }^{1}$, and changhong li $^{3}$

${ }^{1}$ University of Science and Technology Beijing

${ }^{2}$ Institute of Acoustics Chinese Academy of Sciences

${ }^{3}$ Affiliation not available

April 27, 2020

\begin{abstract}
This work aims to investigate the anisotropic fracture and energy dissipation characteristics of marbles cored along an angle of $0^{\circ}, 30^{\circ}, 60^{\circ}$ and $90^{\circ}$ with respect to interbed planes, subjected to multi-level cyclic loading conditions. Rock fatigue deformation, strength, lifetime and dissipated energy first decreases and then increases with increasing interbed orientation, they get to the minimum for sample having $30^{\circ}$ interbed orientation. Rock stiffness degradation is significant with the increase of cyclic level and the stiffness evolution is affected by interbed structure. The incremental rate of dissipated energy becomes faster with increase of cyclic loading level and it presents an abrupt increasing trend at the last cyclic loading level. A damage evolution model was first established based on the dissipated energy to describe the two-phase damage accumulation characteristics. It suggests that the proposed model fits well to the testing data and favorably represents the non-linear characteristics of damage accumulation.
\end{abstract}

\section{Hosted file}

Anisotropic dynamic fracture and energy dissipation of interbedded marble-FFEMS4.27.docx available at https://authorea.com/users/299009/articles/446086-anisotropic-dynamic-fracture-andenergy-dissipation-characteristics-of-interbedded-marble-subjected-to-multi-level-uniaxialcompressive-cyclic-loading 